SCientiæ studia, São Paulo, v. 7, n. 2, p. 251-69, 2009

\title{
st \\ Criatividade, liberdade e dignidade: impactos do darwinismo no behaviorismo radical
}

Carolina LAURENTI

\begin{abstract}
茴
RESUMO

A teoria da evolução pela seleção natural de Charles Darwin influenciou de modo decisivo a filosofia de B. F. Skinner denominada Behaviorismo Radical. Este artigo tem o objetivo de discutir o impacto do darwinismo na elaboração do modelo de explicação do comportamento behaviorista radical chamado seleção pelas consequências. Em primeiro lugar, examina-se como a ideia de seleção é fundamental para elucidar o papel do ambiente na explicação do comportamento. Em seguida, argumenta-se que a interpretação skinneriana da origem da variação comportamental abre espaço para a defesa da possibilidade da criatividade humana. Por fim, discute-se como a substituição da mente criativa (homem autônomo) pelos processos de variação e seleção na explicação do comportamento lança nova luz sobre o tratamento da liberdade e dignidade humanas no Behaviorismo Radical.
\end{abstract}

Palavras-chave • Behaviorismo radical. Darwinismo. Seleção pelas consequências. Criatividade. Liberdade. Dignidade.

Há lugar em uma análise científica do comportamento para o eu iniciador, criador, criativo? Tendo prescindido de Deus como criador, deve a ciência prescindir também daquela imagem de Deus chamada Homem? (Skinner, 1989, p. 27).

\section{INTRODUÇÃO}

Estudiosos de história e epistemologia da psicologia reconhecem a influência do darwinismo $^{1}$ na constituição e consolidação de vários sistemas psicológicos (Chiesa, 1994;

1 Mayr (2005) considera que há, pelo menos, nove usos diferentes do termo ‘darwinismo' (cf. p. 133-147). Neste texto, entendemos 'darwinismo', basicamente, como uma teoria que explica a evolução dos seres vivos em termos da inter-relação entre variação e seleção (cf. Mayr, 2005, p. 147). 
Herrnstein \& Boring, 1971 [1966]; Ratner, 1975). A teoria do psicólogo norte-americano B. F. Skinner (1904-1990) chamada Behaviorismo Radical não foge à regra. Em vários momentos de sua obra, Skinner (19533, p. 90, 430; 1974, p. 114; 1984a [1981]; 1984,b; 1989, p. 90, 129) teceu analogias entre sua teoria do comportamento e a seleção natural. Não obstante, a influência do darwinismo na teoria skinneriana torna-se flagrante quando examinamos o modelo de explicação behaviorista radical denominado seleção pelas consequências (Skinner, 1984a [1981]). Referindo-se a esse modelo, o afamado biólogo Richard Dawkins (1984) disse que "seleção pelas consequências é uma boa frase" (p. 4.86), pois coloca uma ênfase correta sobre a diferença entre a ideia de seleção ativa operada pela escolha de um agente, e a seleção que se dá mediante processos darwinianos cegos, desprovidos de propósito e intenção.

Sob a ótica desse modelo, o comportamento é entendido como o produto da ação seletiva das consequências sobre as variações comportamentais (Skinner, 1984a). Na verdade, esse modelo explica a origem e evolução do comportamento seguindo uma estrutura chamada tríplice contingência, que especifica um conjunto de condições antecedentes, respostas e consequências. Nessa perspectiva, um novo comportamento é gerado quando, diante de condições específicas, respostas (variações) são selecionadas pelas consequências que produzem. Essa estrutura de explicação é semelhante à empregada por Darwin em A origem das espécies (2004 [1859]), ao descrever a evolução em termos de condições de vida, variação e seleção (cf. Moxley, 2001).

Além desses elementos, a teoria skinneriana compartilha outros aspectos do darwinismo. Darwin propôs uma explicação da origem e evolução dos seres vivos em termos naturais, sem recorrer a poderes ou forças sobrenaturais. Com isso, não só questionou a crença na constância do mundo e a causa da adaptação dos organismos, mas, principalmente, a posição única do homem no mundo dos seres vivos (cf. Mayr, 2009, p. 29). Semelhantemente, Skinner (1984a) explicou a origem e evolução do comportamento em termos das relações entre o organismo e seu ambiente, sem apelar para um agente mental, imaterial e substancial. Ao fazer isso, Skinner também destituiu o homem de seu lugar privilegiado: o de autor ou iniciador do comportamento. Ao substituir a mente criativa pelos processos de variação e seleção, Skinner (1974) foi acusado de defender a tese de que o homem é um mero fantoche estando à mercê das determinações inexoráveis do ambiente natural e social, tornando inexequíveis a criatividade, a liberdade e a dignidade humanas.

Este texto tem o objetivo de criticar essa ilação. Considerando as influências do darwinismo na teoria skinneriana, discutiremos, aqui, como a explicação do comportamento em termos dos processos de variação e seleção lança nova luz sobre o tratamento da criatividade, liberdade e dignidade no Behaviorismo Radical. 


\title{
1 Ciência e comportamento humano
}

Skinner (1953) acreditava na possibilidade de desenvolvimento de uma ciência do comportamento humano. Essa ciência deveria não apenas promover uma melhor compreensão do comportamento, mas também contribuir para o desenvolvimento de tecnologias que acarretassem melhores condições de vida para o homem. À época de Skinner, a necessidade da psicologia contribuir para a construção de um contexto social menos coercitivo e ameaçador era premente. Skinner (1987) descreve uma situação de completo caos social que, desafortunadamente, encontra ecos precisos na contemporaneidade:

\begin{abstract}
A maioria das pessoas atentas concorda que o mundo está em sério perigo. Uma guerra nuclear pode significar um inverno nuclear que destruiria todas as coisas vivas; os combustíveis fósseis não vão durar para sempre, e muitos outros recursos críticos estão se aproximando da exaustão; a Terra se torna regularmente menos habitável; e tudo isso é exacerbado por um crescimento populacional que resiste ao controle. $\mathrm{O}$ calendário não está claro, mas a ameaça é real (Skinner, 1987 , p. o1).
\end{abstract}

Para Skinner (1987), esses problemas globais se devem, em grande parte, ao comportamento humano. Além do mais, pondera Skinner (1971), tais problemas não poderiam ser resolvidos por uma tecnologia física e biológica. É certo que as tecnologias desenvolvidas a partir dessas ciências contribuíram para aliviar as mazelas humanas. Não obstante, muitas das melhorias dispostas por essas tecnologias não são colocadas em prática. É, pois, necessário mudar o comportamento humano. Indo direto ao ponto, Skinner declara: "o que precisamos é de uma tecnologia do comportamento" (1971, p. 5).

Todavia, continua Skinner, a ciência da qual essa tecnologia pode ser extraída não tem se desenvolvido de maneira satisfatória. Enquanto as ciências físicas e biológicas progrediram substancialmente desde os tempos de Platão e Aristóteles, um avanço correspondente não se faz notar nas ciências que se preocupam com questões sociais humanas: "com respeito à tecnologia, temos caminhado a passos gigantescos no controle do mundo físico e biológico, mas nossos sistemas políticos, educacionais e mesmo econômicos (...) não melhoraram muito" (Skinner, 1971, p. 11).

Na perspectiva skinneriana, esse descompasso está relacionado com o modo como as ciências que lidam com o homem explicam o comportamento. Ao passo que as explicações em termos de agentes possuidores (como uma alma ou élan), propósitos e 
essências fazem parte apenas do passado da física e da biologia, elas ainda participam do terreno psicológico (cf. Skinner, 1971). Não é incomum ouvir que um menor infrator comete delitos devido a um distúrbio de personalidade; que não há melhorias nas condições de vida da população devido à falta de vontade política por parte dos governantes. Atribui-se ainda o comportamento humano à natureza humana, e as pessoas são rotuladas segundo traços de caráter, capacidades e habilidades nos moldes de uma psicologia das diferenças individuais.

Na psicologia, o protótipo das explicações pré-científicas encontra-se na explicação do comportamento em termos de um homem interior autônomo (cf. Skinner, 1971). Aqui, o comportamento é entendido como mera manifestação, sintoma ou subproduto da ação de um "eu interior", que nada mais é do que "um centro do qual o comportamento emana. Ele inicia, dá origem, cria e, ao fazer isso, permanece divino, como o era para os gregos. Afirmamos que é autônomo e, do ponto de vista de uma ciência do comportamento, isso quer dizer milagroso" (Skinner, 1971, p. 14). O homem autônomo é a expressão de um eu essencial, de uma existência íntima, de um indivíduo separado que se encontra atrás do comportamento. Nessa concepção, "o que a pessoa faz é de importância secundária ao que a pessoa é" (Chiesa, 1994, p. 97). Em termos mais técnicos, enquanto o homem autônomo assume a posição de uma "variável independente", o comportamento apresenta-se como a "variável dependente".

Mas por que as ciências do homem têm dificuldade de se desvencilhar dessas explicações? Skinner (1971) reconhece que há poucas alternativas a esses tipos de teorias. Entretanto, as ciências do comportamento podem tomar caminho semelhante àquele trilhado pelas ciências física e biológica, abandonando "causas" espúrias. Para Skinner uma explicação científica adequada deve recorrer ao ambiente - um ambiente que se refere à história evolutiva da espécie (filogênese), à história de vida do indivíduo (ontogênese) e a contextos sociais chamados culturas: "a tarefa de uma análise científica é explicar como o comportamento de uma pessoa, enquanto sistema físico, está relacionado às condições sob as quais a espécie humana evoluiu e às condições sob as quais o indivíduo vive" (Skinner, 1971, p. 14).

Em suma, uma concepção científica transfere a explicação do comportamento do homem autônomo para o ambiente: "a ciência do comportamento substitui o agente autônomo pelo ambiente" (Skinner, 1971, p. 184). Sendo assim, uma das principais tarefas da ciência é elucidar a natureza e o papel do ambiente na explicação do comportamento. 
Criatividade, liberdade e dignidade...

\section{O PAPEL DO AMBIENTE À LUZ DO DARWINISMO}

De acordo com Skinner, defender a tese de que a explicação do comportamento deve se dar recorrendo ao ambiente, e não ao homem autônomo, não é o bastante. É preciso entender como o ambiente funciona, pois "o papel do ambiente não é, de modo algum, claro" (1971, p. 16). Durante a história, o papel do ambiente na explicação do comportamento sofreu uma série de mudanças. Por exemplo, até o século xviı o ambiente era considerado apenas o lugar onde as coisas aconteciam. Em outras palavras, ao ambiente não era atribuído nenhum status causal: os animais se comportavam de diferentes maneiras em diferentes lugares, mas não porque estavam em ambientes diferentes. Enfim, era mais fácil perceber o que os organismos faziam com o mundo ao seu redor, do que atentar para o que o mundo fazia com eles.

"A primeira evidência do contrário foi o tipo conspícuo [de ação ambiental] pushpull" (Skinner, 1999a, p. 399). Segundo Skinner, Descartes foi um dos primeiros a atribuir esse papel ativo ao ambiente antecipando a noção de reflexo. Os reflexos passaram a ser estudados e examinados no século xIx. Aqui, o ambiente exercia uma ação propulsora, que foi chamada pelos fisiologistas de estímulo, e o seu efeito sobre o organismo foi denominado resposta. A relação entre estímulo e resposta constituía o reflexo. Pavlov, por sua vez, ampliou o escopo das relações reflexas ao mostrar como novos reflexos podiam ser estabelecidos por meio do condicionamento clássico. Com isso, nascia a psicologia estímulo-resposta (S-R), que entendia o comportamento como uma mera reação aos estímulos (cf. Skinner, 1971).

Dando continuidade à história das concepções de ambiente, Skinner (1969, p. 3-10) argumenta que a psicologia estímulo-resposta padecia de uma séria omissão: desconsiderava a ação do ambiente depois das respostas do organismo. Era, pois, necessário examinar as consequências das ações. Foi só no final do século xIx, com os experimentos de Thorndike, que a relação temporal entre respostas e suas consequências foi examinada segundo os cânones do método científico. A lei do efeito de Thorndike foi uma das primeiras formulações científicas que mostraram o papel das consequências sobre o comportamento: "quando uma pessoa age, as consequências podem fortalecer sua tendência a agir novamente da mesma maneira" (Skinner, 1999a, p. 399).

Sobre esse ponto, Skinner destaca ainda que a lei do efeito "deve muito à teoria darwiniana" (1999a, p. 399). Isso porque a teoria da evolução foi responsável por uma mudança radical no papel do ambiente ocorrida no século xix. Trata-se da ênfase na função seletiva do ambiente: 
O ambiente não apenas cutuca ou sacode, ele seleciona. Sua função é semelhante à da seleção natural, e foi deixado de lado pela mesma razão. Agora é evidente que devemos considerar o que o ambiente faz a um organismo não somente antes, mas depois de sua resposta. O comportamento é modelado e mantido por suas consequências. Uma vez que esse fato seja reconhecido, podemos formular a interação entre organismo e ambiente de forma bem mais ampla (Skinner, 1971, p. 18).

Esse background elucida a expressão skinneriana "seleção pelas consequências", que caracteriza o modelo explicativo behaviorista radical. Ora, "seleção" remete ao processo darwinista de seleção. E “consequências” diz respeito à lei do efeito de Thorndike. Essas noções foram fundamentais para Skinner (1953, 1971) reformular sua concepção do papel do ambiente. É digno de nota que, no início de sua obra, Skinner (1999c, 1991) defendia uma concepção muito similar à do paradigma reflexo: "o conceito de reflexo é importante na descrição do comportamento porque é, por definição, um enunciado da necessidade dessa relação [entre estímulo e resposta]" (Skinner, 1999c, p. 495).

Não obstante, a extensão dos processos de variação e seleção à explicação do comportamento e a ênfase nas consequências das ações demarcam um afastamento radical de Skinner do paradigma reflexo. Há diferenças notáveis entre esses modelos. Em primeiro lugar, a ação seletiva do ambiente é explicada em termos probabilísticos. Dito de outro modo, o produto da ação do ambiente sobre o organismo é a geração de tendências ou probabilidades: “o comportamento humano é controlado (...) ao mudar as condições ambientais das quais é uma função. O controle é probabilístico. O organismo não é forçado a se comportar de uma dada maneira; simplesmente aumenta-se a probabilidade de ele fazer algo" (Skinner, 1973, p. 259). Assim, enquanto no modelo reflexo o objetivo era descrever relações de necessidade entre organismo e ambiente, no modelo de seleção pelas consequências as relações entre antecedentes, respostas e consequências são descritas segundo o vocabulário das probabilidades.

Em segundo lugar, a ideia de ambiente no modelo de seleção pelas consequências é modificada. Na explicação estímulo-resposta a ênfase recai no ambiente imediato, ou seja, nas condições antecedentes contíguas à ocorrência da resposta. Já no modelo skinneriano a explicação reside nas consequências produzidas ao longo do tempo. Nas palavras de Skinner, as variáveis das quais o comportamento é função "encontram-se no seu ambiente imediato e em sua história ambiental” (1953, p. 31).

Assim, é importante esclarecer que na explicação skinneriana do comportamento as consequências em jogo são as passadas, e não as futuras. São as consequências passadas que dão sentido (isto é, função) ao comportamento atual. Com efeito, as condições antecedentes atuais só configuram uma situação para a emissão da resposta se, 
no passado, condições semelhantes participaram da seleção do comportamento pelas consequências. Dessa forma, o comportamento atual está contextualizado na história de seleção pelas consequências. É justamente esse caráter histórico que afasta a teoria consequencialista skinneriana de uma explicação teleológica do comportamento: "no lugar de dizer que um homem se comporta por causa das consequências que seguirão seu comportamento, diremos simplesmente que ele se comporta por causa das consequências que seguiram um comportamento semelhante no passado" (Skinner, 1953, p. 87).

A partir dessa breve história do papel do ambiente, podemos aquilatar a assertiva skinneriana de que uma mera transferência da explicação do comportamento do homem autônomo para o ambiente não basta (cf. Skinner, 1971). Há várias concepções de ambiente em jogo. Por isso, a tese skinneriana de que o ambiente substitui o homem autônomo deve ser entendida à luz de seu tratamento do papel do ambiente, que é esclarecido, em um primeiro momento, por meio do processo de seleção darwiniano e pela lei do efeito de Thorndike.

Desse modo, podemos dizer que Skinner (1971, 1999a) explica o comportamento descrevendo relações de dependência probabilística entre as ações do indivíduo e suas consequências seletivas, diante de circunstâncias antecedentes específicas. No entanto, seria incorreto e incompleto dizer que o modelo de explicação skinneriano é definido apenas em termos da ação seletiva das consequências. Na esteira da teoria evolutiva darwiniana, Skinner (1999b) não explica o comportamento somente por meio da seleção. Sem variação não há o que selecionar. É preciso, portanto, ter em conta as variações comportamentais.

\section{UMA NOTA SOBRE O ESTATUTO DA VARIAÇÃO NO DARWINISMO}

A seleção natural é um processo que ocorre em duas etapas: a variação e a seleção propriamente dita (cf. Mayr, 2005). Desse modo, a variação é apenas uma etapa preliminar do processo evolutivo, que é seguida pela seleção. Sob esse prisma, Mayr afirma que não há incompatibilidade, mas sim, uma relação de cooperação entre variação aleatória e seleção: "nenhuma seleção pode ter lugar sem variação, e a variação não tem sentido sem seleção subsequente (eliminação). O aparente antagonismo entre variação e seleção pode ser agora interpretado como um processo construtivo" (2005, p. 173). Isto posto, podemos dizer que variação e seleção têm estatuto epistêmico positivo na explicação evolutiva: a evolução é explicada pela seleção de variações.

Uma coisa é dizer que a origem e evolução dos seres vivos são esclarecidas pela inter-relação entre variação e seleção; outra bem diferente é indagar acerca da própria 
origem das variações sobre as quais a seleção opera. Sobre esse ponto, Mayr declara que o acaso é usualmente considerado uma das fontes de produção da variação: "na produção de variação o acaso domina" (2008, p. 256). Contudo, essa assertiva exige esclarecimento. Darwin (2004 [1859]), por exemplo, admitia que as variações ocorriam ao acaso. Entretanto, invocar o acaso como fator evolutivo provocou inúmeras controvérsias, pois como um órgão tão perfeito como o olho poderia ser produto do acaso?

Ora, à época de Darwin, em que predominava um determinismo estrito, admitir a participação do acaso na produção de fenômenos biológicos soava como uma declaração explícita contra o empreendimento científico. Tanto foi assim que a seleção natural darwiniana recebeu a pecha de "lei da mixórdia" (Mayr, 2005, p. 129). A ideia de variação colocava em xeque a determinação dos fenômenos, o que contribuiu para a difícil aceitação da teoria da evolução segundo a seleção natural: "por todo o século XIx, os cientistas físicos ainda eram deterministas em sua visão, e um processo tão indeterminado quanto a seleção natural era inaceitável para eles" (Mayr, 2005, p. 129).

A despeito de ter contribuído para a aceitação posterior do conceito de acaso na biologia, Darwin (2004 [1859]) parecia ainda estar sob influência do determinismo de sua época. Isso porque o recurso ao acaso era apenas um paliativo à ignorância de todos os determinantes da variação:

Até o presente momento, sempre que nos referimos às variações comuns e diversas nos animais e vegetais em estado doméstico, e que ocorrem em grau menor nos que se encontram em estado natural, atribuímos sua ocorrência ao acaso. Porém, trata-se, sem dúvida, de um modo de falar totalmente errado, o que demonstra nossa ignorância quanto às causas de cada variação em particular (Darwin, 2004 [1859], p. 197).

Darwin, nesse ponto, não se desvencilhou da visão lamarckista da variação em A origem das espécies (cf. Lennox, 1992). Sob essa ótica, a variação era entendida como uma resposta a exigências adaptativas, que desempenhavam uma função causal direta na produção de variação herdável. Dito de outro modo, a variação não era randômica com respeito à adaptação. No que diz respeito à variação, a diferença de Lamarck e Darwin para os biólogos contemporâneos é que os últimos reconhecem a variação randômica (cf. Lennox, 1992; Mayr, 2005).

Todavia, dizer que uma variação é aleatória não significa, em absoluto, que ela não está em relação de dependência com outros eventos (cf. Mayr, 2008). O caráter randômico da variação deve ser entendido em relação à necessidade do organismo. Isso significa que as variações não são tratadas como respostas a demandas adaptativas. Dessa forma, "acaso" ou "randômico" significa "não afetado por requerimentos 
adaptativos", um produto do "acaso", não do "planejamento" (Lennox, 1992, p. 3oo). Mayr esclarece o ponto: "quando autores contemporâneos falam de variação ao acaso, não contestam a existência de forças moleculares causais, mas sim a alegação de que tal variação genética seja uma resposta adaptativa às necessidades de um organismo. Uma resposta como essa nunca ocorre" (2005, p. 108). Como sugere Mayr, a variação não é qualquer coisa que possa aparecer sem relação com outros eventos. Avariação tem leis: “a variação está submetida a muitas leis que a regulam, mas somente algumas são conhecidas, e mesmo assim de forma obscura" (Darwin, 2004 [1859], p. 74).

Não obstante, o reconhecimento de leis da variação não implica, pelo menos para alguns biólogos contemporâneos, a defesa de um determinismo (cf. Lewontin, 2002; Mayr, 2005). A variação é um fenômeno indeterminado, no sentido de que ela é produto de leis probabilísticas, características dos fenômenos biológicos: "regularidades são abundantes no mundo vivo também, mas em sua maioria, não são universais, nem sem exceção; elas são probabilísticas e muito restritas no espaço e tempo" (Mayr, 2008, p. 94).

\section{A IMPORTÂNGIA DA VARIAÇÃO NA EXPLIGAÇÃO DA GRIATIVIDADE}

Skinner (1999b, 1974) emprega raciocínio semelhante à teoria evolucionista da origem das espécies para explicar o surgimento de um novo comportamento. O termo origem, aqui, é fundamental, como o próprio Skinner (1999b) chama a atenção: “o termo chave no título de Darwin é 'origem’. A novidade pode ser explicada sem apelar a um planejamento prévio se mudanças randômicas na estrutura forem selecionadas por suas consequências" (Skinner, 1999a, p. 399). Já nesse excerto Skinner sugere como novos comportamentos são originados. No caso da origem de novas espécies, variações que promovem a sobrevivência dos organismos nos ambientes em que vivem são selecionadas por essa consequência; ao passo que aquelas prejudiciais são eliminadas com a extinção do organismo. Esse processo seletivo é cumulativo e lento, de sorte que depois de um longo período de tempo uma nova espécie pode ser criada. Ora, como uma nova "espécie" de comportamento é originada? Referindo-se ao comportamento operante, Skinner responde: "como traços acidentais que surgem da mutação são selecionados por suas contribuições à sobrevivência, assim, variações acidentais que surgem no comportamento são selecionadas por suas consequências reforçadoras" (1974, p. 114).

Com efeito, novos comportamentos surgem da seleção de variações comportamentais. Skinner tece uma analogia que deixa essas relações mais claras: 
A origem do comportamento é muito parecida com a origem das espécies. Quando aspectos particulares de um operante são fortalecidos por reforçamento diferencial, novas características passam a existir sob a forma de variações. $A$ existência de variações está na natureza do comportamento assim como está na natureza de um traço genético e, da mesma forma, novos comportamentos e novos genomas emergem quando variações são selecionadas por suas consequências (1989, p. 129; grifos meus).

Skinner reconhece explicitamente que a variação é intrínseca ao comportamento. Em outras palavras, é inerente aos fenômenos comportamentais variar, mudar. Dito isso, cabe mais uma questão: qual é a origem das variações comportamentais? Essa pergunta, como examinamos há pouco, é de suma importância, pois a explicação da origem da variação foi um dos grandes problemas enfrentados por Darwin (cf. Mayr, 2005). Skinner (1974), seguindo a linha de alguns biólogos contemporâneos (cf. Lewontin, 2002; Mayr, 2005), explica a origem da variação recorrendo ao acaso:

Que o acaso pode desempenhar um papel na produção de qualquer coisa importante como a matemática, a ciência ou a arte foi questionado com frequência. (...). Ainda assim, todas as biografias de escritores, compositores, artistas, cientistas, matemáticos e inventores revelam a importância de acidentes na produção do comportamento original. O conceito de seleção é novamente a chave. As mutações na teoria genética e evolucionária são randômicas, e as topografias de respostas selecionadas pelo reforçamento são, se não randômicas, pelo menos não necessariamente relacionadas com as contingências sob as quais elas são selecionadas (Skinner, 1974, p. 114).

Em outro trecho, Skinner mostra certa resistência a recorrer ao acaso: "podemos não gostar de creditar qualquer aspecto de uma pintura bem-sucedida ao acaso (chance)" ( 1999b, p. 386). A despeito dessa hesitação, ele, no final das contas, reconhece que admiti-lo pode ser um passo promissor, em termos de explicação e modificação do comportamento. Na sequência do trecho supracitado, Skinner completa: "mas se estivermos dispostos a admitir que o acaso (chance) faz uma contribuição, podemos dar passos para aprimorar as casualidades (chances)" (p. 386).

Como podemos fomentar as casualidades? Ora, se comportamentos novos, criativos surgem como resultado da seleção de variações, e se a fonte de produção de variações é o acaso, então, é possível aumentar a probabilidade de ocorrência de respostas originais mimetizando o acaso: "o papel do acaso (chance) pode ser assumido, e ampliado, por um arranjo deliberado" (Skinner, 1968, p. 180), ou ainda, "podemos apren- 
der não apenas a tirar proveito dos acidentes (...), mas a produzi-los" (p. 180). Mas como podemos emular o acaso? O acaso pode ser entendido como o elemento que afrouxa o liame entre antecedentes, respostas e consequências, dando espaço para a ocorrência de variações comportamentais. Com efeito, simular o acaso é tornar o controle de um ambiente menos preciso e é encorajar perturbações no ambiente (Skinner, 1999b, p. 386).

Skinner dá um exemplo desse estratagema no contexto do ensino. Podemos aumentar as chances de ocorrência de comportamentos originais (ou de alunos criativos) tornando o controle de estímulos menos preciso na sala de aula como, por exemplo, incentivando o emprego de metáforas, paráfrases e a leitura menos precisa de textos. Sobre esse ponto, Skinner admite que "a proposta colide com a valorização tradicional da perfeição" (1968, p. 176).) Por outro lado, podemos encorajar perturbações incentivando o comportamento exploratório ou a curiosidade, valorizando a produção do novo, do diferente e desestimulando a mera repetição e reprodução.

Antes de encerrar o assunto, vale chamar a atenção para o fato de que o produto desse arranjo de contingências é imprevisível. Aqui, apenas se aumenta a probabilidade de ocorrência de respostas originais. O resultado pode ser tão somente a mediocridade - nesse sentido, podemos dizer que a ocorrência de variação é uma condição necessária, mas não suficiente para a criatividade humana. E nos casos em que respostas criativas surgem, não podemos prever quais serão elas. Isso porque "há sempre um elemento de mistério na emissão de qualquer resposta operante. Um estímulo nunca exerce controle completo" (Skinner, 1968, p. 137).

Diante desse quadro, podemos dizer que Skinner (1968, 1971, 1974, 1999b,) parece ter encontrado na teoria evolutiva (especialmente em sua versão neodarwinista) uma explicação científica para a origem da variação - explicações que, até então, abriam as portas para conceitos mentalistas, como uma mente criativa. Enfim, podemos dizer que a explicação skinneriana da origem das variações comportamentais abre espaço para a defesa da possibilidade da criatividade humana. Isso porque o acaso afrouxa o vínculo entre antecedentes, respostas e consequências permitindo a ocorrência de espontaneidade, de variação, de criatividade.

\section{Papel do ambiente versus homem autônomo}

Tendo em vista a explicação skinneriana da origem e evolução do comportamento, é possível agora ampliar os paralelos entre Darwin e Skinner. O primeiro explicou a origem e evolução das espécies por meio da teoria da seleção natural. Ao fazer isso, Darwin (2004 [1859]) substituiu o deus criador pelos processos de variação e seleção. Skinner 
(1971), por sua vez, explicou a origem e evolução dos comportamentos em termos de um modelo denominado seleção pelas consequências. Com isso, destituiu o homem autônomo ou a mente criativa de seu poder explicativo, substituindo-os pelos processos de variação e seleção.

A transferência de deus na biologia, e do homem autônomo na psicologia, para o ambiente tem o seu ônus. A teoria da evolução pela seleção natural demorou pelo menos oitenta anos para ser aceita entre os biólogos (Mayr, 2005, p. 133). Como disse Mayr: "a teoria teve rejeição quase universal" (2005, p. 128). Do mesmo modo, Skinner também considera que a explicação do comportamento em termos de seleção e variação encontra resistência na psicologia: "ciência é comportamento humano, e também o é a oposição à ciência” (1971, p. 22). Uma das reações a esse modelo é a agressão: “o que as pessoas fazem em relação à visão científica de homem é chamá-la de errada, humilhante e perigosa, argumentam contra ela, atacam-na e atacam os que a propõem ou defendem" (p. 212). Segundo Skinner, isso acontece, sobretudo, porque a concepção científica de homem destrói os reforçadores habituais da sociedade ocidental: a liberdade e a dignidade. Examinemos, então, esse processo de “destruição".

\section{LIBERDADE}

De acordo com Skinner, a visão tradicional (não-científica) concebe a pessoa como livre e responsável. Liberdade, nesse caso, significa que o comportamento não tem causa: "[o homem] é autônomo no sentido de que seu comportamento não é causado. Portanto, ele pode ser considerado responsável pelo que faz e merecidamente punido pelas suas transgressões" (1971, p. 19). Diferente disso, a concepção científica de homem, na perspectiva skinneriana, defende que o comportamento é "causado" ou "controlado"² por variáveis ambientais. Aqui, o tratamento skinneriano da liberdade acom-

\footnotetext{
2 $O$ termo 'controle' empregado amiúde por Skinner contribuiu para fomentar inúmeras controvérsias sobre sua teoria psicológica. Sobre esse ponto, a filha de Skinner, Julie Vargas, disse: "se meu pai cometeu um erro, foi nas palavras que escolheu. As pessoas ouvem a palavra controle e acham fascista. Se meu pai tivesse dito que as pessoas eram informadas por seus ambientes, ou inspiradas por seus ambientes, ninguém teria tido um problema" (Slater, 2004, p. 38-9). Dizer que o comportamento é controlado significa, simplesmente, que o comportamento está em relação de dependência com outros eventos. Dito de outro modo, Skinner emprega o termo para chamar a atenção para o fato de que o comportamento tem "causas", e que uma ciência do comportamento deve identificá-las e descrevê-las. Todavia, vale lembrar que dizer que o comportamento é controlado não implica a tese de que o comportamento é determinado. É preciso averiguar a natureza desse controle para sustentar essa ilação. Como já mencionamos, Skinner (1973) advoga que o controle é probabilístico, mostrando, com isso, mais afinidades com concepções científicas de indeterminismo (Heisenberg, 1999 [1958]; Peirce, 1992 [1892]; Popper, 1988 [1956]). Para uma discussão mais detalhada sobre as noções de determinismo e indeterminismo no Behaviorismo Radical, cf. Laurenti (2009).
} 
panha o raciocínio da tese da transferência da explicação do comportamento do homem autônomo para o controle ambiental. Ora, essa tese é contrária à concepção de que o homem não é livre quando seu comportamento é controlado e é livre quando seu comportamento não é controlado. Nesse ponto, Skinner (1968, 1971) diverge das explicações mentalistas, pois não entende a liberdade como o produto da ação ou da vontade de um agente interior, que pensa, delibera e decide independentemente das condições do ambiente natural e social.

Lembrando ainda que a natureza desse controle natural e social é probabilística, Skinner (1971) defenderá a possibilidade de liberdade em termos de relações controladoras, e não como ausência de controle. Assim, o homem não é livre quando seu comportamento é produto de um dado tipo de controle. Da mesma forma, o homem é livre quando seu comportamento também está sob uma forma de controle específico. Nesse caso, a pergunta que importa a Skinner (1971) é: quais são as condições, ou quais são os controles, que configuram "escravidão" e quais são aqueles que produzem liberdade?

Há, pelo menos, duas situações em que o homem não é livre. Em primeiro lugar, o homem não é livre quando seu comportamento está sob controle de estimulação aversiva; quando, por exemplo, "gasta todo o seu tempo evitando fome, peste, perigo, e fortes controles pessoais e institucionais" (Skinner, 1968, p. 172). Os homens também não são livres quando estão sob o controle de contingências de reforço positivo imediato, mas que produzem, em longo prazo, consequências aversivas: "ninguém força o jogador compulsivo a jogar; não obstante, ele não é livre. (...). Nem é livre o cientista ou o artista, cujo trabalho é fortemente afetado por sucesso financeiro ou aclamação profissional" (Skinner, 1968, p. 172). Com efeito, a luta pela liberdade é uma luta contra formas de controle aversivo, imediato ou postergado, arranjados por outras pessoas.

O tratamento skinneriano da liberdade em termos de relações controladoras é capaz de revelar situações exploradoras e escravizantes que não são denunciadas pela literatura da liberdade, já que esta última, ao fundamentar-se na concepção tradicional de homem, entende a liberdade em termos de sentimentos ou estados da mente (Skinner, 1971). Ao tratar a liberdade sob esse prisma, tal literatura é incapaz de libertar o homem de um controle sutil, que não fomenta fuga ou revolta, mas que produz consequências aversivas remotas.

Em tese, a literatura da liberdade não conseguiria atingir o "escravo feliz", aquele cujo comportamento tem reforço positivo imediato, mas que, em última análise, não é livre. Para entendermos o cerne da crítica skinneriana às limitações da concepção tradicional de liberdade, vejamos como Skinner explica a relação entre o reforçamento positivo e o sentimento de felicidade ou liberdade. Na perspectiva behaviorista radical, as consequências do comportamento têm dois efeitos sobre o indivíduo: alteraram a probabilidade do comportamento e produzem sentimentos (cf. Skinner, 1974). 
Em contingências de reforço positivo, as consequências do comportamento usualmente produzem sentimentos tais como confiança, diligência, expectativa, liberdade, autoestima elevada, dentre outros (Skinner, 1974, p. 57-61; 1989, p. 13-25, 30-1). Ora, no caso da "falsa liberdade", a pessoa sente-se livre, pois está sob controle de reforço positivo imediato. Porém, tal reforço está condicionado a consequências aversivas remotas. Por isso, nessas condições, o homem não élivre. Daí a importância de se discutir a liberdade em termos de relações controladoras, e não apenas em termos dos sentimentos que as contingências engendram: "a distinção é particularmente importante quando as contingências não geram fuga ou contra-ataque" (Skinner, 1971, p. 38).

Isso fica claro, por exemplo, nas famigeradas políticas do "pão e circo", tão comuns na época das eleições. As pessoas têm reforçadores imediatos, sentem-se felizes, livres, aquietam-se, e não atentam para os esquemas de corrupção e desvio de dinheiro público, que em longo prazo contribuem para a manutenção de sua condição de miséria. Nota-se, portanto, a sutileza e perversidade desse tipo de controle, que escraviza o indivíduo sem gerar revolta.

Com essa discussão, Skinner denuncia outro raciocínio falacioso da literatura da liberdade. Skinner admite que essa literatura tem sido eficaz na luta contra formas de controle aversivo, ao ajudar a identificar pessoas que produzem condições opressoras e ao propor maneiras de fugir delas ou enfraquecer seu poder. Assim, "os vilões característicos dessa literatura são os tiranos, padres, generais, capitalistas, professores severos e pais dominadores" (1971, p. 30). Não obstante, a literatura da liberdade faz uma generalização indevida: se o controle aversivo é ruim e a liberdade é boa, todo controle é ruim - "o que é negligenciado é o controle que não produz consequências aversivas em momento algum” (p. 42). Contra essa generalização, Skinner afirma que a luta pela liberdade não seria uma luta pela liberdade do controle, mas de certos tipos de controle.

É, pois, necessário ir além da liberdade, tal como entendida pela literatura da liberdade. Isso significa deslocar a discussão da liberdade do indivíduo, notadamente daquilo que ele sente, para inseri-la no contexto das relações sociais. Lutar pela liberdade é buscar relações sociais menos exploradoras e escravizantes, isto é, menos aversivas: "para tornar o ambiente social tão livre quanto possível do controle aversivo, não precisamos destruir o ambiente ou fugir dele; precisamos remodelá-lo" (Skinner, 1971, p. 42). 


\section{Dignidade}

No caso da dignidade, temos um encaminhamento semelhante ao da liberdade. A concepção científica de homem defendida por Skinner é incompatível com a tese tradicional da dignidade. Basicamente, esta opera mediante a dissimulação das variáveis controladoras do comportamento. Reconhecemos a dignidade ou valor de alguém quando damos crédito pelo que fez: "o grau dessa valorização é inversamente proporcional à evidência das causas de seu comportamento" (1971, p. 58). Assim, quanto mais sabemos sobre as condições que levaram uma pessoa a agir de uma dada maneira, menos a admiramos ou a censuramos pelos seus atos. Em direção oposta, a concepção científica de homem busca justamente a explicitação das variáveis controladoras. Ora, quando admitimos o controle do comportamento, o próximo passo é buscar as variáveis envolvidas nesse controle (ou seja, as causas do comportamento). Isso é necessariamente inconsistente com a noção tradicional de dignidade, que só aparece quando se desconhece essas causas.

Todavia, a concepção tradicional de homem parece seguir uma lógica, no mínimo, paradoxal. Aqui, o elogio e a atribuição de culpa são inversamente proporcionais ao conhecimento das causas. Seguindo esse raciocínio, os elogios são contidos se as causas são evidentes. Com efeito, muitas vezes dissimulamos ou ocultamos o controle para sermos reconhecidos e reivindicar um mérito que não é nosso. Por exemplo, embora um palestrante se valha de subterfúgios como fichas e anotações para orientar seu discurso, ele tenta mostrar que fala de memória e improviso, sendo reconhecido por isso (cf. Skinner, 1971). Da mesma forma, exemplifica Skinner, omitimos as fontes de uma ideia para não lhe retirar a atmosfera de originalidade.

Por outro lado, quando a situação é atribuição de culpa por algum ato cometido, observa-se uma tendência oposta: busca-se, agora, explicitar ao máximo o tipo de controle em jogo para atenuar as punições (cf. Skinner, 1971). Em outras palavras, no caso de absolvição de culpa, a concepção tradicional de homem não parece se opor à busca das variáveis de controle, defendida pela concepção científica. $O$ advogado, por exemplo, descreve o ambiente miserável, hostil e violento no qual o acusado viveu, na tentativa de amenizar a pena por latrocínio. O marido justifica à sua amada e aos filhos a falta de carinho e atenção alegando sua árdua rotina de trabalho. $O$ aluno atribui seu mau desempenho à incapacidade de lecionar do professor. O professor, por sua vez, absolve-se da culpa pela má qualidade do ensino alegando as precárias condições de trabalho, e assim por diante.

Por que no caso da culpa aludimos às condições ambientais, e quando se trata de mérito pessoal tentamos negá-las ou dissimulá-las? Como se vê, em ambas as situações, o que parece estar em jogo são relações controladoras. É o caso, de irmos além da 
dignidade, tal como entendida pela concepção tradicional de homem, e buscar formas de relações controladoras mais "dignas". Isso significa, por exemplo, que fiquemos mais dependentes das coisas do que do elogio alheio para nos comportamos; que haja uma distribuição de reforçadores mais justa e igualitária, isto é, contingente e proporcional à quantidade de comportamento (cf. Skinner, 1971).

Em suma, a discussão skinneriana da liberdade e dignidade é feita em termos da elucidação das variáveis ambientais que influenciam (controlam) o comportamento, e não sob a ótica do homem autônomo. Ainda sobre a natureza do controle do comportamento, não custa repetir: Skinner (1968, 1999b) afastou-se da defesa de um controle necessário e inexorável. Ora, ele enfatiza a natureza probabilística do controle, e considera o papel do acaso e das variações comportamentais no processo de seleção do comportamento pelas suas consequências.

\section{Conclusão}

Na esteira de Darwin, Skinner vislumbrou uma proposta psicológica que tenta superar uma série de dificuldades enfrentadas por projetos de psicologia científica. Com a crítica à interpretação mentalista dos fenômenos psicológicos Skinner pretendia derrubar o "criacionismo" na psicologia. Se na biologia esse criacionismo se manifestava na figura de um deus criador e onisciente, na psicologia ele se revela na ideia de um homem autônomo, uma mente criativa, que origina e comanda nossas ações. À semelhança de Darwin, Skinner apresentou uma explicação secular do comportamento, que passou a ser entendido como resultado de processos de variação e seleção, e não mais como produto de uma mente substancial e imaterial.

A crítica ao mentalismo abriu o flanco para que Skinner (2004) também questionasse a sua contraparte exata: o materialismo (notadamente na sua feição eliminativista). Se na biologia, o criacionismo ganha roupagens modernas como a teoria do design inteligente, na psicologia, esse criacionismo se apresenta na forma de um cognitivismo. Em uma palestra proferida na American Psychological Association oito dias antes da sua morte, Skinner disse: "a ciência cognitiva é o criacionismo da psicologia”. Isso porque algumas vertentes do cognitivismo estão substituindo a mente pelo cérebro: agora é o cérebro que inicia e dá origem ao comportamento. O cérebro é o agente criador!

Skinner não está dizendo que a neurologia e a fisiologia não podem contribuir para a compreensão do comportamento. Skinner quer chamar a atenção para o fato de que essas ciências lidam com o produto (corpo com cérebro) e não com o processo de produção: "o cérebro é parte do corpo, e o que ele faz é parte do que o corpo faz. O que o cérebro faz é parte do que precisa ser explicado" (Skinner, 1990, p. 1206). As ciências 
do comportamento (etologia, antropologia e psicologia) devem lidar com os processos de variação e seleção que explicam o comportamento. Com a crítica ao cognitivismo, podemos dizer que Skinner viu uma psicologia além do materialismo eliminativo, sem descartar a importância das ciências do cérebro.

Com a destituição da mente criadora na psicologia, Skinner viu uma ciência além do determinismo, sem eliminar a regularidade comportamental. $\mathrm{O}$ acaso é a fonte da variabilidade. É o elemento de acaso que afrouxa o liame entre antecedentes, respostas e consequências. Os eventos não estão atados, presos uns aos outros de maneira fixa, imutável e inexorável. Há um espaço genuíno para a ocorrência de variação, de criatividade. Por outro lado, o comportamento humano também é processo: exibe uma regularidade, uma tendência. O comportamento é também probabilidade. É o processo de seleção que gera novas tendências, novas probabilidades: "se novas formas de comportamento são criadas, elas são criadas pela seleção" (Skinner, 1990, p. 1208). Nesse sentido, podemos dizer que na teoria skinneriana coabitam acaso (variação) e regularidade (seleção).

Ao transferir a explicação do comportamento do homem autônomo para o ambiente, Skinner também viu além da liberdade e dignidade tal como concebidas pela teoria do homem autônomo. Lutar pela liberdade e dignidade é lutar pela construção de contextos sociais menos opressores. É voltar os olhos para as consequências de nossas ações e avaliar o quanto elas contribuem para a manutenção de relações coercitivas, escravizadoras e humilhantes. É fazer uma reflexão sobre quais valores orientam nossas ações.

Mas ao ver uma psicologia além do mentalismo, materialismo, determinismo e das concepções tradicionais de liberdade e dignidade, Skinner talvez tenha se colocado além do seu tempo. E isso poderia explicar a resistência, ainda atual, em relação a suas propostas (Carrara, 2005). Resta, então, perguntar se seremos capazes de ir além da visão que entende o homem como o centro e a origem de nossas ações.

Agradecimentos. Este trabalho desenvolve partes de minha tese de doutoramento, intitulada Determinismo, indeterminismo e behaviorismo radical, que contou com o apoio da FAPESP por meio de bolsa de doutorado.

Carolina Laurenti

Doutora em Filosofia, Universidade Federal de São Carlos, Brasil. carolinapsicologia@hotmail.com 


\section{ABSTRAGT}

Skinner's Radical Behaviorism was strongly influenced by Charles Darwin's evolution theory by means of natural selection. This article aims to discuss the impact of the Darwinism in the development of the radical behaviorist explicative model called selection by consequences. In first place, we examine the importance of the concept of selection in the elucidation of the role of environment. Next, it is argued that Skinnerian interpretation of the origin of behavioral variation provides the means to the defense of the possibility of human creativity. Finally, it is discussed how the renouncement of the creative mind (autonomous man), and the subsequent adoption of variation and selection processes, sheds light on human liberty and dignity in Radical Behaviorism.

KeYwords $\bullet$ Radical behaviorism. Darwinism. Selection by consequences. Creativity. Freedom. Dignity.

\section{REFERÊNGIAS BIBLIOGRÁFICAS}

Carrara, K. Behaviorismo radical: crítica e metacrítica. 2.ed. rev. e atual. São Paulo: Edunesp, 2005.

Chiesa, M, Radical behaviorism: the philosophy and the science. Boston: Authors Cooperative, 1994.

Darwin, C. A origem das espécies. Tradução J. Green. São Paulo: Martin Claret, 2004, [1859].

Dawkins, R. Replicators, consequences, and displacement activities. The Behavioral and Brain Sciences, 7 , 4, p. 4,86-87, 1984 .

Gilgen, A. R. (Ed.). Psicologia científica contemporânea. Tradução H. E. G. de O. Graeff. São Paulo: EPU, 1975 .

Heisenberg, W. Physics and philosophy: a revolution in modern science. New York: Prometheus Books, 1999 [1958].

Herrnstein, R. J. \& Boring, E. G. (Ed.). Textos básicos de história da psicologia. Tradução D. M. Leite. São Paulo: Herder/Edusp, 1971 [1966].

Houser, N. \& Kloesed, C. J. W. (Ed.). The essencial Peirce. Bloomington: Indiana University Press, 1992.

Laurenti, C. Determinismo, indeterminismo e behaviorismo radical. São Carlos, 2009. Tese (Doutorado em Filosofia). Centro de Educação e Ciências Humanas, Universidade Federal de São Carlos.

Lennox, J. G. Philosophy of biology. In: Salmon, M. et al. (Ed.). Introduction to the philosophy of science. New Jersey: Prentice Hall, 1992. p. 269-3o9.

Lewontin, R.A tripla hélice: gene, organismo e ambiente. Tradução J. Vegas Filho. São Paulo: Companhia da Letras, 2002 [1998].

Mayr, E. Biologia, ciência única. Tradução M. Leite. São Paulo: Companhia das Letras, 2005 [2004]. . Isto é biologia: a ciência do mundo vivo. Tradução C. Angelo. São Paulo: Companhia das Letras, 2008 [2007].

. O que é a evolução? Tradução R. S. de Biasi e S. C. de Biasi. Rio de Janeiro: Rocco, 2009 [2001].

Moxuey, R. The modern/postmodern context of Skinner's selecionist turn in 1945. Behavior and Philosophy, 29, p. 121-53, 2001.

Peirce, C. S. The doctrine of necessity examined. In: Houser, N. \& Kloesed, C. J. W. (Ed.). The essencial Peirce. Bloomington: Indiana University Press, 1992 [1892]. p. 298-311.

Popper, K. $O$ universo aberto: argumentos a favor do indeterminismo. Tradução N. F. da Fonseca. Lisboa: Publicações Dom Quixote, 1988 [1956].

Ratner, S. C. Psicologia comparada. In: Gilgen, A. R. (Ed.). Psicologia científica contemporânea. Tradução H. E. G. de O. Graeff. São Paulo: EPU, 1975· p. 127-161.

Salmon, M. et al. (Ed.). Introduction to the philosophy of science. New Jersey: Prentice Hall, 1992. 
Criatividade, liberdade e dignidade...

Skinner, B. F. Science and human behavior. New York: The MacMillan Company, $195^{3}$.

. Verbal behavior. Acton: Copley Publishing Group, 1957.

. The technology of teaching. New York: Appleton-Century-Crofts, 1968.

. Contingencies of reinforcement: a theoretical analysis. New York: Appleton-Century-Crofts, 1969. . Beyond freedom and dignity. New York: Alfred A. Knopf, 1971.

. Answers for my critics. In: WheELER, H. (Ed.). Beyond the punitive society. San Francisco: Freeman, 1973. p. $256-66$.

. About behaviorism. New York: Alfred A. Knopf, 1974.

. Selection by consequences. The Behavioral and Brain Sciences, 7, 4, p. 477-81, 1984a [1981].

. The evolution of behavior. Journal of the Experimental Analysis of Behavior, 41, 2, p. 217-21, 1984,b.

. Why we are not acting to save the world. In: Upon further reflections. Englewood Cliffs, NJ:

Prentice-Hall, 1987. p. 1-14.

. Recent issues in the analysis of behavior. Columbus: Merrill Publishing Company and Bell \& Howell

Information Company, 1989.

. Can psychology be a science of mind? American Psychologist, 45, 11, p. 1206-10, 1990.

. The behavior of organisms: an experimental analysis. Cambridge: B. F. Skinner Foundation, 1991

[1938].

. A lecture on "having" a poem. In: VARgas, J. S. (Ed.). Cumulative record: definitive edition. Acton: Copley Publishing Group, 1999a [1972]. p. 391-4,01.

. Creating the creative artist. In: VARGAS, J. S. (Ed.). Cumulative record: definitive edition. Acton: Copley

Publishing Group, 1999b [1970]. p. 379-90.

. The concept of the reflex in the description of behavior. In: VArGas, J. S. (Ed.). Cumulative record: definitive edition. Acton: Copley Publishing Group, 1999c [1931]. p. 475-503.

. B. F. Skinner. Direção: Carlos Augusto Freire Júnior e Tom Soares. Brasil. Yourubá Produções Audiovisuais, 2004. Documentário. 1 DVD (29 min.). Tradução de Noreen Campbell de Aguirre. Original publicado em 1990 pela American Psychology Association com o título B. F. Skinner's keynote address: lifetime scientific contribution remarks.

Stater, L. Abrindo a caixa de Skinner: a corrida de ratos de B. F. Skinner. In: Mente e cérebro: dez experiências impressionantes sobre o comportamento humano. Tradução V. P. Assis. Rio de Janeiro: Ediouro, 2004. p. 16-44.

Vargas, J. S. (Ed.). Cumulative record: definitive edition. Acton: Copley Publishing Group, 1999.

Wheeler, H. (Ed.). Beyond the punitive society. San Francisco: Freeman, 1973.

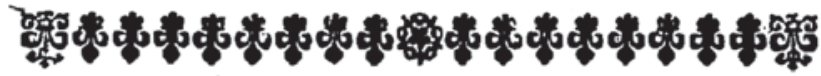

